\title{
Axillary Lymph Node Status in Early-Stage Breast Cancer Patients with Sentinel Node Micrometastases $(0.2-2 \mathrm{~mm})$
}

\author{
Johannes Bargehr ${ }^{\mathrm{a}, \mathrm{b}} \quad$ Michael Edlinger $^{\mathrm{c}} \quad$ Michael Hubalek $^{\mathrm{b}} \quad$ Christian Marth $^{\mathrm{b}} \quad$ Roland Reitsamer $^{\mathrm{a}}$ \\ ${ }^{a}$ Breast Center, Paracelsus Medical University Salzburg, ${ }^{b}$ Department of Obstetrics and Gynecology, Innsbruck Medical University, \\ ${ }^{c}$ Department of Medical Statistics, Informatics and Health Economics, Innsbruck Medical University, Austria
}

\section{Keywords}

Breast cancer · Biopsy · Lymph node: dissection, metastases, status · Micrometastases - Sentinel lymph node $\cdot$ Risk factors

\section{Summary}

Background: Omission of axillary lymph node dissection (ALND) is increasingly becoming the new standard of care for patients with sentinel lymph node micrometastases (SNMMs). However, a formidable proportion of patients is afflicted with non-sentinel node (NSN) macrometastatic tumor burden. Methods: Over 1 decade 5,000 patients underwent sentinel node biopsies (SNB) at 2 certified breast cancer centers in Austria. All available cases of SNMM during this time period were reviewed. Clinical, tumor and lymph node parameters were analyzed using univariate and multivariate analysis to retrieve predictors for further NSN involvement. Results: We identified 216 patients with SNMMs, of whom 181 subsequently underwent ALND. Of the latter patients, $16 \%$ ( $n=29 / 181$ ) presented with NSN axillary metastases. ALND revealed NSN macrometastases in $10.5 \%$ ( $n=19 / 181$ ) of all the investigated patients, and $66 \%$ of the NSN-positive patients ( $n=19 / 29)$. In $28 \%(n=8 / 29$ ) of the NSN-positive patients, more than 1 macrometastasis was detected. The number of removed sentinel nodes was found to be a significant predictor ( $p=0.007$ ) for NSN involvement. Conclusion: In this retrospective investigation of breast cancer patients with SNMMs, a substantial proportion exhibited involvement of NSNs. Macrometastases accounted for the largest fraction of NSN tumor burden. Refraining from ALND in the face of SNMMs may entail substantial micro- and macrometastatic tumor burden in the remaining axillary lymph node basin.

\author{
Schlüsselwörter \\ Brustkrebs · Biopsie - Lymphknoten: Metastasen, \\ Status - Axilladissektion - Mikrometastasen . \\ Wächterlymphknoten · Risikofaktoren
}

\section{Zusammenfassung}

Hintergrund: Bei Patientinnen mit Mikrometastasen im Wächterlymphknoten wird die Axilladissektion als therapeutischer Standard zunehmend verlassen. Dennoch finden sich bei einem beträchtlichen Anteil der Patientinnen Makrometastasen in Nicht-Wächterlymphknoten. Methodik: Innerhalb eines Jahrzehnts wurde an 5000 Patientinnen eine Wächterlymphknoten-Biopsie durchgeführt. Alle zugänglichen Fälle von Mikrometastasen im Wächterlymphknoten wurden untersucht. Klinische Parameter, Tumorkriterien, sowie Lymphknoten-Parameter wurden unter der Verwendung von univariater und multivariater Statistik analysiert, mit dem Ziel Prädiktoren für eine weitere axilläre Beteiligung zu identifizieren. Ergebnisse: Wir konnten 216 Patientinnen mit Mikrometastasen im Wächterlymphknoten ermitteln, von denen sich 181 anschließend einer Axilladissektion unterzogen. Von allen Studienteilnehmern präsentierten sich $16 \%$ ( $n=29 / 181$ ) mit axillären Lymphknotenmetastasen. Die Axilladissektion zeigte Makrometastasen der NichtWächterlymphknoten in $10,5 \%$ ( $n=19 / 181)$ von allen untersuchten Patientinnen und in $66 \%$ ( $n=19 / 29)$ der Patientinnen mit Metastasen in Nicht-Wächterlymphknoten. In letzterer Gruppe waren in $28 \%$ ( $n=8 / 29$ ) multiple Metastasen vorhanden. Die Anzahl der entfernten Wächterlymphknoten war ein signifikanter Prädiktor für metastatische Besiedelung in Nicht-Wächterlymphknoten ( $p=0,007)$. Schlussfolgerung: In dieser retrospektiven Analyse von BrustkrebsPatientinnen mit Mikrometastasen im Wächterlymphknoten zeigte ein substantieller Anteil metastatische Besiedelung von Nicht-Wächterlymphknoten, von denen Makrometastasen den größten Anteil ausmachten. Das Verlassen der Axilladissektion bei Mikrometastasen im Wächterlymphknoten bedingt eine mikro- und makrometastatische Tumorlast in weiteren axillären Lymphknoten, deren pathologische Evaluierung wir hier explizit beschreiben.

\section{KARGER \\ Fax +497614520714 \\ Information@Karger.com}

www.karger.com (c) 2013 S. Karger GmbH, Freiburg

$1661-3791 / 13 / 0083-0187 \$ 38.00 / 0$

Accessible online at:

www.karger.com/brc 


\section{Introduction}

The axillary lymph node (ALN) status is one of the most important prognostic factors in early-stage breast cancer patients, and sentinel node biopsy (SNB) is a reliable and thoroughly validated ALN-staging procedure [1,2].

SNB has replaced ALN dissection (ALND) in patients with negative SNs due to its reduced physical and psychological morbidity. While there is general scientific agreement on how to treat macrometastases and submicrometastases, controversy remains on how to properly deal with SN micrometastases (SNMMs). This has resulted in divergent surgical approaches when SNMMs are present, i.e. whether to perform ALND or to spare patients further axillary surgery [3].

Lymphedema, entailing constricted arm mobility, pain, seroma formation and infection represent some of the most serious sequelae of ALND [4, 5]. In the face of these consequences, over the last decade investigations have tried to assess whether clearing the remaining axillary lymph node basin results in a superior outcome for patients with micrometastatic SNs or constitutes overtreatment. However, results on survival and non-sentinel node (NSN) involvement rates have been inconsistent, leading to disagreement about a standard treatment of SNMM [6-16].

Here we address both the question of further axillary surgery in patients with SNMM, explicitly reviewing the axillary basin after SNB, and the attempt to identify clinical predictors for NSN involvement, ideally to provide possible risk assessment on a case-by-case basis.

\section{Patients and Methods}

In this retrospective cross-sectional analysis we searched the databases of 2 certified breast cancer centers, at the Paracelsus Medical University Salzburg and the Innsbruck Medical University, for micrometastases detected in SNBs performed in early-stage breast cancer patients (between the years 1999 and 2009). Our search yielded 216 patients with SNMMs, of whom 181 subsequently underwent ALND; 35 patients rejected the procedure. All patients gave informed consent to participate in the study. The study was conducted according to the provisions of the Helsinki Declaration and was approved by the ethics committees of the 2 universities.

The following parameters were recorded: age, menopausal status, side and location of the primary tumor within the breast, tumor size, histological type of the tumor, grade, estrogen receptor status, progesterone receptor status, HER2 status and lymphovascular invasion. SNMM identification was performed on frozen serial tissue section with routine immunohistochemistry (IHC). Furthermore, the number of SNs, excluding peri-sentinel nodes, the number of harvested NSNs in ALND and the overall number of positive lymph nodes were evaluated. The 35 patients who decided not to undergo ALND after SNB indicated SNMMs were excluded from further analysis.

On the day before surgery, following the given protocol used by both centers, a radioactive tracer was applied by periareolar injection and, directly before surgery, a blue dye by peritumoral or subareolar injection. Histopathological workup of the SNs comprised 250- $\mu$ m sections with subsequent hematoxylin and eosin (H\&E) staining and IHC.
The distribution of the data was examined using histograms, QQ plots, skewness and kurtosis, and was accepted as normal if skewness and kurtosis ranged between -1 and 1 . In the univariate analysis, the NSNnegative group $(n=152)$ was compared to the NSN-positive group $(n=29)$. To compare continuous variables between the NSN-positive and the NSN-negative groups, the 2-sample T test was used when the normality assumption was satisfied, and the Mann-Whitney U test for data that did not demonstrate normal distribution. The Pearson's chi-squared test was used for categorical variables and Fisher's exact test if the validity was violated. A p value of $<0.05$ was considered significant.

A binary logistic regression model was applied to determine the impact of the recorded explanatory variables on the response variable, which was defined as positive or negative NSNs in the remaining axillary basin. The PASW Statistics version 18 was used for statistical analysis.

\section{Results}

\section{Patient and Tumor Characteristics}

Of the 5,000 patients who underwent SNB, 216 were found to have SNMMs. The mean age of the SNMM cohort was 59 years (median, 58; range, 25-89). The primary tumor characteristics are listed in table 1 . Of these patients, $67.1 \%$ $(\mathrm{n}=145)$ were postmenopausal. The mean tumor size was $18 \mathrm{~mm}$ (median, 16; range, 2-80). Bloom-Richardson tumor grades I, II and III were found in $8.3 \%(\mathrm{n}=18), 71.8 \%$ $(\mathrm{n}=155)$ and $19.9 \%(\mathrm{n}=43)$ of the patients, respectively. Invasive ductal carcinoma was identified in $86.1 \%(\mathrm{n}=186)$ and invasive lobular carcinoma in $9.7 \%(\mathrm{n}=21)$. Lymphovascular invasion was present in $26.4 \%(n=57)$ of the patients. None of these parameters differed significantly between the groups with negative and positive NSN status.

\section{SN Characteristics}

The SN characteristics are shown in table 2. The mean number of SNs identified was 2.33 (median, 2; range, 1-5). In $82.3 \%(\mathrm{n}=178)$ of cases, only $1 \mathrm{SN}$ was found to be positive, while the remaining $17.7 \%(n=38)$ of cases had $\geq 2$ positive SNs. The exact size of the SNMMs was available for $63.4 \%$ $(\mathrm{n}=137)$ of patients, with $42.6 \%(\mathrm{n}=92)$ presenting a deposit of $<1 \mathrm{~mm}$, and $20.8 \%(\mathrm{n}=45)$ SNMMs of $>1 \mathrm{~mm}$. Frozen tissue sections were positive in 26 cases, whereas standard tissue staining $(\mathrm{H} \& \mathrm{E})$ yielded a positive result in $150 \mathrm{SNs}$ and routine IHC in 90 SNs.

\section{NSN Involvement}

The lymph node characteristics of the patients with NSN involvement are summarized in table 3. SNB yielded micrometastases in the SN in 216 patients, and of these patients, 181 subsequently underwent ALND; 35 patients rejected the procedure. Further, $16 \%$ of patients with micrometastases in the $\mathrm{SN}(\mathrm{n}=29)$ presented with tumor deposits in NSNs. Of the patients with SNMMs and positive NSNs, 41\% (n=12) demonstrated lymphovascular invasion of the primary tumor. ALND revealed macrometastatic deposits in the NSNs of $10.5 \%(n=19 / 181)$ of patients (mean size: 4.8 , range: $2.1-10)$, 
Table 1. Baseline characteristics of the primary tumor

\begin{tabular}{|c|c|c|}
\hline & $\mathrm{n}$ & $\%$ \\
\hline \multicolumn{3}{|l|}{ Location } \\
\hline UOQ & 116 & 53.7 \\
\hline UIQ & 29 & 13.4 \\
\hline LOQ & 26 & 12.0 \\
\hline LIQ & 16 & 7.4 \\
\hline Central & 14 & 6.5 \\
\hline Multilocular & 15 & 6.9 \\
\hline \multicolumn{3}{|l|}{ Side } \\
\hline Left-sided & 117 & 54.2 \\
\hline Right-sided & 99 & 45.8 \\
\hline \multicolumn{3}{|l|}{ Histology } \\
\hline IDC & 186 & 86.1 \\
\hline ILC & 21 & 9.7 \\
\hline Other & 9 & 4.2 \\
\hline \multicolumn{3}{|l|}{ Grade } \\
\hline 1 & 18 & 8.3 \\
\hline 2 & 155 & 71.8 \\
\hline 3 & 43 & 19.9 \\
\hline \multicolumn{3}{|c|}{ Lymphovascular invasion } \\
\hline Absent & 159 & 73.6 \\
\hline Present & 57 & 26.4 \\
\hline \multirow{2}{*}{\multicolumn{3}{|c|}{ ER }} \\
\hline Negative & & \\
\hline Low & 30 & 13.9 \\
\hline Intermediate & 67 & 31.0 \\
\hline High & 89 & 41.2 \\
\hline \multicolumn{3}{|l|}{ PR } \\
\hline Negative & 46 & 21.3 \\
\hline Low & 32 & 14.8 \\
\hline Intermediate & 62 & 28.7 \\
\hline High & 76 & 35.2 \\
\hline \multicolumn{3}{|l|}{ HER2 } \\
\hline Negative & 139 & 64.4 \\
\hline Positive & 77 & 35.6 \\
\hline \multicolumn{3}{|l|}{ Tumor size, $\mathrm{mm}$} \\
\hline $1-5$ & 6 & 2.8 \\
\hline $6-10$ & 36 & 16.7 \\
\hline $11-15$ & 64 & 29.6 \\
\hline $16-20$ & 51 & 23.6 \\
\hline $21-30$ & 41 & 19.0 \\
\hline$>30$ & 18 & 8.3 \\
\hline \multicolumn{3}{|c|}{ UOQ = upper outer quadrant, UIQ = upper inner quadrant, } \\
\hline \multicolumn{3}{|c|}{$\mathrm{LOQ}=$ lower outer quadrant, LIQ = lower inner quadrant } \\
\hline \multicolumn{3}{|c|}{ IDC = invasive ductal carcinoma, ILC = invasive lobular carcinoma, } \\
\hline $\mathrm{ER}=$ estrogen $\mathrm{r}$ & erone & \\
\hline
\end{tabular}

representing $66 \%(\mathrm{n}=19 / 29)$ in the NSN-positive group; $28 \%$ $(\mathrm{n}=8 / 29)$ had macrometastases in more than $1 \mathrm{NSN}$. The size of the micrometastases was in the upper range of the definition of micrometastases in 10 patients $(1.9-2.0 \mathrm{~mm})$.

\section{Predictors of NSN Involvement}

To determine predictors of NSN involvement, the number of SNs removed, lymphovascular invasion, tumor grade and size of the primary tumor as well as identification of SNMM by $\mathrm{H} \& \mathrm{E}$ and IHC staining were entered in the multivariate analysis. Of these parameters, the number of SNs removed was

Table 2. Baseline characteristics of the SNs

\begin{tabular}{lrr}
\hline & $\mathrm{n}$ & $\%$ \\
\hline Number of SNs removed & 71 & 32.9 \\
1 & 73 & 33.8 \\
2 & 72 & 33.3 \\
$\geq 3$ & 178 & 82.3 \\
Positive SNs & 38 & 17.7 \\
$\quad 1 \quad 2$ & 92 & 42.6 \\
$\geq 2$ & 45 & 20.8 \\
Micrometastasis size & 79 & 36.6 \\
$\quad$ 1 mm & & \\
> mm & 120 & 55.6 \\
Unknown & 26 & 12.0 \\
Metastasis identification on frozen section & 70 & 32.4 \\
$\quad$ Negative & 63 & 29.2 \\
Positive & 150 & 69.4 \\
$\quad$ Not performed & 3 & 1.4 \\
Metastasis identification with H\&E & & \\
$\quad$ Negative & 126 & 58.3 \\
Positive & 90 & 41.7 \\
Not performed & 61 & 28.2 \\
Metastasis identification by IHC & & \\
Negative & & \\
Positive & & \\
Identification by IHC only & &
\end{tabular}

Table 3. Lymphnode characteristics of the 29 patients with tumor deposits in NSNs

\begin{tabular}{|c|c|c|c|c|c|c|c|c|c|}
\hline Patient no. & LVI & $\begin{array}{l}\text { SNs, } \\
\mathrm{n}\end{array}$ & $\begin{array}{l}\text { NSNs, } \\
\mathrm{n}\end{array}$ & $\begin{array}{l}\text { Overall } \\
\text { positive } \\
\text { LNs, n }\end{array}$ & $\begin{array}{l}\text { SNMMs, } \\
\mathrm{n}\end{array}$ & $\begin{array}{l}\text { Size of } \\
\text { SNMM, } \\
\text { mm }\end{array}$ & $\begin{array}{l}\text { NSN micrometasta- } \\
\text { ses, } \\
\mathrm{n}\end{array}$ & $\begin{array}{l}\text { NSN macrometas- } \\
\text { tases, } \\
\mathrm{n}\end{array}$ & $\begin{array}{l}\text { Size of NSN macro- } \\
\text { metastases, mm }\end{array}$ \\
\hline 1 & - & 2 & 14 & 3 & 2 & 0.5 & 2 & - & - \\
\hline 3 & + & 5 & 16 & 4 & 3 & 1.2 & - & 4 & 5.0 \\
\hline 4 & + & 2 & 20 & 3 & 4 & 1.5 & 1 & - & - \\
\hline 5 & + & 5 & 12 & 2 & 2 & 0.4 & 1 & - & - \\
\hline 6 & - & 3 & 20 & 2 & 1 & 0.6 & - & 1 & 3.0 \\
\hline 7 & - & 1 & 21 & 2 & 2 & 1.9 & 1 & - & - \\
\hline 8 & + & 2 & 10 & 2 & 1 & 1.2 & 1 & - & - \\
\hline 9 & - & 1 & 23 & 2 & 2 & 1.0 & - & 1 & 2.1 \\
\hline 10 & + & 2 & 24 & 3 & 2 & 1.5 & 2 & - & - \\
\hline 11 & + & 1 & 23 & 2 & 2 & 0.4 & 1 & - & - \\
\hline 12 & - & 1 & 11 & 2 & 3 & 1.9 & - & 1 & 3.0 \\
\hline 13 & - & 2 & 16 & 2 & 1 & 1.2 & - & 1 & 2.1 \\
\hline 14 & + & 3 & 12 & 3 & 1 & 1.9 & - & 2 & 2.1 \\
\hline 15 & - & 1 & 19 & 2 & 1 & 1.9 & - & 1 & 5.0 \\
\hline 16 & - & 1 & 25 & 2 & 2 & 0.5 & - & 1 & 3.0 \\
\hline 17 & + & 1 & 20 & 2 & 1 & 0.2 & - & 2 & 5.0 \\
\hline 18 & - & 1 & 15 & 2 & 1 & 0.5 & 1 & - & - \\
\hline 20 & - & 4 & 11 & 2 & 1 & 2.0 & - & 1 & 3.0 \\
\hline 21 & - & 4 & 24 & 3 & 2 & 0.4 & 2 & - & - \\
\hline 22 & - & 4 & 14 & 2 & 1 & 1.5 & - & 1 & 2.1 \\
\hline 23 & - & 1 & 22 & 2 & 1 & 1.9 & - & 1 & 10.0 \\
\hline 24 & + & 1 & 18 & 3 & 1 & 2.0 & - & 2 & 6.0 \\
\hline 25 & + & 2 & 17 & 2 & 1 & 1.5 & - & 1 & 3.0 \\
\hline 26 & - & 1 & 18 & 2 & 1 & 2.0 & - & 1 & 5.0 \\
\hline 27 & - & 1 & 19 & 3 & 1 & 0.2 & - & 2 & 7.0 \\
\hline 28 & - & 1 & 17 & 3 & 1 & 2.0 & - & 2 & 7.0 \\
\hline 29 & + & 1 & 20 & 6 & 1 & 2.0 & - & 5 & 6.0 \\
\hline
\end{tabular}

LVI = lymphovascular invasion, + = present, $-=$ absent, $\mathrm{SN}=$ sentinel node

$\mathrm{SNMM}=$ sentinel node micrometastases, NSLN = non-sentinel node, $\mathrm{LN}=$ lymph node. 
significantly associated $(\mathrm{p}=0.007)$ with the response variable (positive or negative NSN axillary status). Lymphovascular invasion showed a trend towards significance as a positive predictor $(\mathrm{p}=0.076)$. Grading, size of the primary tumor, identification of SNMM by H\&E and IHC staining were not found to be significant predictors in this cohort.

\section{Discussion}

The prime objectives of breast cancer surgery are local and regional control of the disease and improved survival of the patients. However, whether these aims can be accomplished with ALND omission invariably for all patients with SNMMs remains under scrutiny.

Some authors reported that patients with SNMMs have a significantly worse survival rate, advocating adjuvant therapy in this patient group [6-12], while others failed to demonstrate this outcome, arguing for ALND omission [13-16]. Scientific inconsistency regarding the prognostic impact of SNMMs may be attributed to a large number of underpowered studies, lacking randomization and follow-up, as well as poor comparability due to non-standardized histological examination and administration of adjuvant chemotherapy to some patients. Finally, the prevalence of inconsistent study findings concerning SNMM may also be the result of the definition itself.

The risk of harboring additional NSN metastases if the SN is afflicted with micrometastatic disease ( $\mathrm{pN} 1 \mathrm{mi})$ reportedly ranges from 13.4 to $26 \%$ [17-20]. Cserni and colleagues estimated the risk to hover between $10 \%$ and $15 \%$ for micrometastases and isolated tumor cells [21]. Here we report a NSN involvement rate of $16 \%$, which is in the range of previously published results $[20,21]$. It is insistently stated that the generally accepted false-negative rate of SNB is as high as 5\%, which is considerably below the NSN involvement rate reported by this study and by many others.

In our study, $66 \%$ of the NSN-positive patients were found to harbor macrometastatic disease. Although this $66 \%$ fraction of NSN-positive patients appears high, it is crucial to assess if this high percentage has an impact on patient outcome.

The ACOSOG Z0011 trial demonstrated that for patients with SNMMs spared further axillary surgery, no difference in local, regional and distant recurrence rates could be observed. Even ALND omission in the presence of SN macrometastases did not result in reduced survival. These results apply to breast cancer patients with a primary tumour of less than $5 \mathrm{~cm}$, a positive $\mathrm{SN}$ count of $\leq 2$ and no clinically detectable lymph node involvement [22].

Galimberti and colleagues studied a cohort of 377 breast cancer patients with micrometastases in $1 \mathrm{SN}$. They found the 5 -year overall survival to be $97.3 \%$, and the accumulative incidence of axillary recurrence to be $1.6 \%$. The authors concluded that patients with small tumours of $\leq 2 \mathrm{~cm}$ and low to intermediate grade might safely be spared ALND. However, patients with high-grade tumours of $>2 \mathrm{~cm}$ demonstrated a significantly worse axillary recurrence rate. According to the authors ALND should still be performed in these patients [23].

However, it has also been demonstrated that patients with SN macrometastases have a significantly worse survival compared to SN-negative patients. Recently, Weaver and associates studied the impact of occult SN metastases and found that occult nodal macrometastases resulted in a worse prognostic impact with respect to death, any outcome event and distant disease compared to micrometastatic disease [24]. These results are of utmost importance especially taking into account that a considerable proportion of our cohort with SNMMs had more than 1 NSN macrometastasis.

In this study we attempted to identify patients with an increased risk of NSN involvement. Previously, clinical predictors found to display risk for NSN involvement include: age, menopausal status, primary tumor size, grade, number of SNs, number of positive lymph nodes, size of SN metastases, lymphovascular invasion and identification by H\&E or IHC staining [17, 25-29]. In our study the number of SNs removed during the SN procedure was a significant predictor of positive NSN status. Lymphovascular invasion showed a trend towards significance. Both of these findings are in agreement with previously reported results.

At the same time, identification of candidates for ALND omission has only recently started. Therefore, the number of studies is limited and the clinical experience with this approach faces exigent need for enhancement.

The aim of this retrospective investigation was to examine the NSN involvement rate of patients with micrometastatic SNs, ideally to allow a conclusion regarding ALND omission in early-stage breast cancer patients with SNMMs. Of this cohort, $16 \%$ of patients were shown to have NSN involvement, with $28 \%$ of those showing a macrometastatic tumor burden in more than 1 NSN.

Despite this, ALND omission has emerged as the new standard of care for patients with SNMM and, as such, is supported by the Austrian consensus statement [30]. This approach is further backed up by more recent studies [23, 31].

According to the criteria by Giuliano [22], treament of lowrisk patients may safely omit ALND. However, providing equal adjuvant and systemic therapy to this special patient population, as well as to SN-positive patients is paramount $[32,33]$.

However, there is danger in sparing high-risk patients further axillary surgery, notably those who will develop macrometastatic disease in NSNs and hence have a poorer prognosis. Effective steps to identify this group of patients are being taken [34].

Based on recent results [22, 23], ALND omission is going to be the new standard of care for patients with SNMM, despite the associated metastatic tumor burden in the NSNs, which has been demonstrated by this study and others. 


\section{Acknowledgements}

The authors wish to thank Henrietta M. Nielsen (Mayo Clinic, Jacksonville, Florida, USA) for critical reading of the manuscript.

\section{Disclosure Statement}

There is no conflict of interest.

\section{References}

1 Krag D, Weaver D, Ashikaga T, et al.: The sentinel node in breast cancer. N Engl J Med 1998;339:941946.

2 Veronesi U, Paganelli G, Viale G, et al.: A randomized comparison of sentinel-node biopsy with routine axillary dissection in breast cancer. $\mathrm{N}$ Engl J Med 2003;349:546-553.

$\checkmark 3$ Wasif N, Ye X, Giuliano AE: Survey of ASCO members on management of sentinel node micrometastases in breast cancer: Variation in treatment recommendations according to specialty. Ann Surg Oncol 2009;16:2442-2449.

-4 Mansel RE, Fallowfield L, Kissin M, et al.: Randomized multicenter trial of sentinel node biopsy versus standard axillary treatment in operable breast cancer: The ALMANAC trial. J Natl Cancer Inst 2006;98:599-609.

5 Langer I, Guller U, Berclaz G, et al.: Morbidity of sentinel lymph node biopsy (SLN) alone versus SLN and completion axillary lymph node dissection after breast cancer surgery: A prospective swiss multicenter study on 659 patients. Ann Surg 2007;245:452-461.

6 6 De Boer M, Van Deurzen CMH, Van Dijck JMAA, et al.: Micrometastases or isolated tumor cells and the outcome of breast cancer. N Engl J Med 2009;361:653-663.

7 Reed J, Rosman M, Verbanac KM, et al.: Prognostic implications of isolated tumor cells and micrometastases in sentinel nodes of patients with invasive breast cancer: 10-year analysis of patients enrolled in the prospective East Carolina University/Anne Arundel Medical Center Sentinel Node Multicenter Study. J Am Coll Surg 2009;208:333340.

$>8$ Kuijt GP, Voogd AC, van de Poll-Franse LV, et al.: The prognostic significance of axillary lymph-node micrometastases in breast cancer patients. Eur J Surg Oncol 2005;31:500-505.

9 Sakorafas GH, Geraghty J, Pavlakis G: The clinical significance of axillary lymphnode micrometastases in breast cancer. Eur J Surg Oncol 2004;30:807816.

10 Colleoni M, Rotmensz N, Peruzotti G, et al.: Size of breast cancer metastases in axillary lymph nodes: Clinical relevance of minimal lymph node involvement. J Clin Oncol 2005;23:1379-1389.

11 Maibenco DC, Dombi GW, Kau TY, et al.: Significance of micrometastases on the survival of women with T1 breast cancer. Cancer 2006;107:1234-1239.
12 Van Rijk MC, Peterse JL, Nieweg OE, et al.: Additional axillary metastases and stage migration in breast cancer patients with micrometastases or submicrometastases in sentinel lymph nodes. Cancer 2006;107:467-471.

13 Hansen NM, Grube B, Turner RR, et al.: Impact of micrometastases in the sentinel node of patients with invasive breast cancer. J Clin Oncol 2009;27:4679-4684.

14 Rutledge H, Davis J, Chiu R, et al.: Sentinel node micrometastases in breast carcinoma may not be an indication for complete axillary dissection. Mod Pathol 2005;18:762-768.

15 Langer I, Guller U, Viehl CT, et al.: Axillary lymph node dissection for sentinel lymph node micrometastases may be safely omitted in early-stage breast cancer patients: Long-term outcomes of a prospective study. Ann Surg Oncol 2009;16:3366-3374.

16 Langer I, Marti WR, Guller U, et al.: Axillary recurrence rate in breast cancer patients with negative sentinel lymph node (SLN) or SLN micrometastases. Prospective analysis of 150 patients after SLN biopsy. Ann Surg 2005;241:152-158.

17 Houvenaeghel G, Nos C, Mignotte H, et al.: Micrometastases in sentinel lymph node in a multicentric study: Predictive factors of non sentinel lymph node involvement. Groupe des chirurgiens de la federation des centres de lute contre le cancer. J Clin Oncol 2006;24:1814-1822.

18 Leidenius MHK, Vironen JH, Riihelä MS, et al.: The prevalence of non-sentinel node metastases in breast cancer patients with sentinel node micrometastases. Eur J Surg Oncol 2005;31:13-18.

19 Gipponi M, Canavese G, Lionetto R, et al.: The role of axillary lymph node dissection in breast cancer patients with sentinel lymph node micrometastases. Eur J Surg Oncol 2006;32:143-147.

20 Cox CE, Kiluk JV, Riker AI, et al.: Significance of sentinel node micrometastases in human breast cancer. J Am Coll Surg 2008;206:261-268.

21 Cserni G, Gregori D, Merletti F, et al.: Metaanalysis of non-sentinel node metastases associated with micrometastatic sentinel nodes in breast cancer. $\mathrm{Br}$ J Surg 2004;91:1245-1252.

22 Giuliano AE, Hunt KK, Ballman KV, et al.: Axillary dissection vs no axillary dissection in women with invasive breast cancer and sentinel node metastasis. JAMA 2011:305:569-575.

23 Galimberti V, Botteri E, Chifu C, et al.: Can we avoid axillary dissection in the micrometastatic sentinel node in breast cancer? Breast Cancer Res Treat 2012;131:819-825.

24 Weaver DL, Ashikaga T, Krag DN, et al.: Effect of occult metastases on survival in node-negative breast cancer. N Engl J Med 2011:364:412-421.

25 Houvenaeghel G, Nos C, Giard S, et al.: A nomogram predictive of non-sentinel lymph node involvement in breast cancer patients with a sentinel lymph node micrometastasis. Eur J Surg Oncol 2009;35:690-695.

26 Carcoforo P, Maestroni U, Querzoli P, et al.: Primary breast cancer features can predict additional lymph node involvement in patients with sentinel node micrometastases. World J Surg 2006;30:16531657.

27 Viale G, MaioranoE, Pruneri G, et al.: Predicting the risk for aditional axillary metastases in patients with breast carcinoma and positive sentinel node biopsy. Ann Surg 2005;241:319-325.

28 Degnim AC, Griffith KA; Sabel MS, et al.: Clinicopathologic features of metastasis in nonsentinel lymph nodes of breast carcinoma patients. Cancer 2003;98:2307-2315.

29 Cserni G, Bianchi S, Vezzosi V, et al.: Sentinel lymph node biopsy in staging small (up to $15 \mathrm{~mm}$ ) breast carcinomas. Results from a European multiinstitutional study. Pathol Oncol Res 2007;13:5-14.

30 Hubalek M, Bartsch R, Gnant M, et al.: Axillary dissection in the case of positive sentinel lymph nodes: Results of the Innsbruck Consensus Conference. Geburtsh Frauenheilk 2012;72:293-298.

31 Barkley C, Burstein H, Smith B, et al.: Can axillary node dissection be omitted in a subset of patients with low local and regional failure rates? Breast J 2012;18:23-27.

32 Pernas S, Gil M, Benitez A, et al.: Avoiding axillary treatment in sentinel lymph node micrometastases of breast cancer: A prospective analysis of axillary or distant recurrence. Ann Surg Oncol 2010;17:772-777.

33 Jafferbhoy S, McWilliams B: Clinical significance and management of sentinel node micrometastasis in invasive breast cancer. Clin Breast Cancer 2012;12:308-312.

34 Houvenaeghel G, Bannier M, Nos C, et al.: Non sentinel node involvement prediction for sentinel node micrometastases in breast cancer: Nomogram validation and comparison with other models. Breast 2012;21:204-209. 